\title{
SOCIAL SECURITY AS A FINANCIAL ASSET: GENDER-SPECIFIC RISKS AND RETURNS
}

\author{
Marianne Baxter \\ Working Paper 8329 \\ http://www.nber.org/papers/w8329 \\ NATIONAL BUREAU OF ECONOMIC RESEARCH \\ 1050 Massachusetts Avenue \\ Cambridge, MA 02138 \\ June 2001
}

David Arsenau provided excellent research assistance for this project. The views expressed herein are those of the authors and not necessarily those of the National Bureau of Economic Research.

(C) 2001 by Marianne Baxter. All rights reserved. Short sections of text, not to exceed two paragraphs, may be quoted without explicit permission provided that full credit, including (C) notice, is given to the source. 
Social Security as a Financial Asset: Gender-Specific Risks and Returns

Marianne Baxter

NBER Working Paper No. 8329

June 2001

JEL No. G2, H3

\begin{abstract}
$\underline{\text { ABSTRACT }}$
Social Security is a financial asset whose 'purchase' is compulsory for most working individuals; the return during the individual's working lifetime is related to the rate of change of aggregate labor income. If an individual's labor income is strongly related to aggregate labor income, then the Social Security asset is a particularly unattractive asset. In this situation, the individual would benefit from a reformed Social Security system that would permit investment of retirement funds in other financial assets. This paper investigates how this aspect of Social Security risk varies across groups of individuals who differ according to gender; education; race; and age. The main finding is that there are important differences across groups in this component of Social Security risk, as captured by the sensitivity of individual-level income growth to changes in the SSWI. This element of risk is most important for women, especially women who are young-to-middle aged and with more education. This analysis suggests that women would have more to gain, compared with men, from a reformed Social Security system.
\end{abstract}

Marianne Baxter

Department of Economics

Boston University

270 Bay State Road

Boston, MA 02215

and NBER

mbaxter@bu.edu 


\section{Introduction}

Social Security represents an important source of retirement wealth for most Americans. As shown in Table 1, Social Security represents a large fraction of the wealth of retirees. ${ }^{1}$ For the median retiree, Social Security represents $25 \%$ of total retirement assets, and $49 \%$ of liquid retirement assets (assets that either yield cash, such as Social Security and pensions, or assets easily converted to cash, such as financial assets and IRAs). Social Security is even more important as a source of retirement income for individuals in the lower lifetime earnings percentiles (i.e., excluding the very lowest 5\%). Further, the Social Security Administration reports that Social Security represents $40 \%$ of all income to the aged population, and it accounts for over $50 \%$ of income for two-thirds of "beneficiary units" (couples or nonmarried persons). Further, Social Security is the only sources of income for $18 \%$ of the aged population. ${ }^{2}$

Social Security is typically viewed as a very safe vehicle for retirement saving-in fact, a major criticism of proposals to reform Social Security to allow participants to hold financial assets such as equities is that there is much higher risk associated with traded financial assets, compared with the traditional Social Security system. A discussion of Social Security risk under the current system would probably focus on the uncertainty regarding future changes in eligibility and the rules for computing benefits. Yet there is an important, frequently overlooked source of Social Security risk that is related to the way that Social Security contributions are indexed, or "marked up" during an individual's working life. The Social Security system uses a measure of aggregate labor income, called the Social Security Wage Index (SSWI), to index individuals' contributions to the Social Security system. The rate of growth of the SSWI is a measure of the return on Social Security contributions during an individual's working life. This return is uncertain, since the future rate of growth of the SSWI is unknown. As with any other financial asset, the average return and risk of Social Security will be important for portfolio construction for an individual during his working life. Because Social Security represents an important source of wealth, yet is not tradable in financial markets, an individual will want to structure the tradable portion of his or her portfolio in a way that hedges, as well as possible,

\footnotetext{
${ }^{1}$ This table describes asset holdings for 51 to 61 year-olds, broken down by income percentiles; the data are from the Health and Retirement Survey, as compiled by Gustman et al. (1997) and Gustman and Steinmeier (1998).

2 "Facts and Figures about Social Security 1998," page 6.
} 
the risk arising from Social Security.

Although Social Security wealth is an important element of an individual's nontraded wealth, by far the largest component of total wealth is an the individual's human capital, which is also nontradable. Table 2, taken from Baxter and King (1999), shows that human capital is the dominant component of an individual's wealth for all individuals except those on the very brink of retirement. For most individuals,the value of human capital is 5 to 20 times as large as the individual's net worth; this ratio is larger for younger individuals, and is smaller for individuals over age 55. But even for these older individuals, human capital is still somewhat larger than net worth.

Given that human capital and Social Security are both important nontraded assets, a key element in evaluating the riskiness of the current Social Security scheme will be the covariance between the return on Social Security (the growth rate of the SSWI) and the return on human capital (roughly, the growth rate of labor income). In particular, the higher is the correlation between the SSWI and the individual's own labor income process, the greater will be the individual's interest in participating in a reformed Social Security system that permits investment of retirement funds in traded financial assets that can help hedge this nontraded risk.

This paper investigates how Social Security risk during the accumulation phase varies across individuals who differ according to gender; education; race; and age group. The main finding is that there are important differences across groups in this component of Social Security risk, as captured by the sensitivity of individual-level income growth to changes in the SSWI. This element of risk is most important for women, especially women who are young-to-middle aged and with more education. This analysis suggests that women would have more to gain, compared with men, from a reformed Social Security system that would permit investment of retirement funds in other forms of financial assets.

The paper is structured as follows. Section 2 describes the data, which are drawn from the PSID and explains how the different sub-groups are structured. This section also presents summary information on the income process for these groups. Section 3 describes the risk/return properties of the Social Security asset, and the relationship between the SSWI and other measures of aggregate economic activity. Section 4 presents an illustrative model of the link between human capital returns and the returns on the Social Security asset. Section 5 contains the paper's empirical results on Social Security risk across socio-economic groups; Section 6 concludes with a 
discussion of the implications of our results for the potential benefits from a reformed Social Security system.

\section{Data}

The data for this study were taken from the Panel Study on Income Dynamics. The data are annual, covering the years 1967-1991. Further details concerning the data can be found in the Data Appendix.

Since the focus of this study is on Social Security risk during the accumulation phase (i.e., during an individual's working life), individuals who were older than 66 years in the last year of our sample (1992) were discarded, as were non-working individuals (those with zero labor income in every year). An individual was listed as "married" if they were married to the same person throughout the sample period; an individual is "single" if they were unmarried throughout the sample. We report results separately for black and white individuals; there were too few individuals in the remaining race categories to perform meaningful analysis. In terms of education, individuals were assigned to one of three educational groups, corresponding to the highest educational level achieved by the end of the sample period. The first group has less than 12 years of education (less than a high school education); the second group has exactly 12 years of schooling (a high school degree), and the third group has more than 12 years of schooling. Finally, we also study three different age groups, where age is measured at the end of the sample period. The first group has age less than 46 years; the second group covers ages 46-55; and the third group covers ages $56-65$.

Table 3 contains information on mean nominal income, income growth, and the variability of nominal income growth for the various groups. As is well known, the level of income is higher for men than for women; is higher for whites compared with blacks, and is generally higher for higher education levels. Single women tend to have higher incomes than married women.

The average change in income is reported in the next-to-last column of Table 3. Because many individuals had zero labor income in some periods, we cannot report the growth rate of income; rather, this column reports the change in the level of nominal labor income from one period to the next. The average income change varies quite a bit across groups, tending to be higher for single females compared with 
married females, and tends to be higher for groups with more education, although this effect is not strong. Finally, the last column reports the average standard deviation of income changes for individuals within the group. That is: the standard deviation of income changes was computed for each individual in the group, and then the average standard deviation across group members was computed; this measure of income volatility varies widely across groups.

\section{Social Security as a Risky Financial Asset}

During their working years, individuals make 'contributions' to the Social Security system. Specifically, the individual and employer together contribute $12.4 \%$ of income up to a cap, which is currently $\$ 72,600$. The Social Security Administration indexes, or 'marks up,' the individual's contributions each year between the contribution date and the individual's retirement date. This is done so that benefits reflect the increase in the general level of wages between the particular working year in which the wages were earned (and contributions were made) and the retirement date.

This indexation is reflected in the computation of the individual's "Average Indexed Monthly Earnings," or AIME. The AIME is constructed as follows. Let $\bar{W}_{t+j}$ denote the national average wage index for year $t+j$, and let $\bar{W}_{t+R}$ denote the national average wage index for the retirement year, $t+R .{ }^{3}$ The worker's indexed earnings $W_{t+j}^{\text {indexed }}$ are computed as follows:

$$
W_{t+j}^{\text {indexed }}=W_{t+j}\left(\frac{\bar{W}_{t+R}}{\bar{W}_{t+j}}\right), j=1,2, \ldots, R .
$$

A worker who contributes $\$ 1$ to Social Security will have that $\$ 1$ 'marked up,' according to the AIME formula (1), by the rate of change of the Social Security wage indexing series for each period between the contribution date and the retirement date. That is:

$\$ 1$ at date t grows to:

$$
\$ 1\left(\frac{\bar{W}_{t+1}}{\bar{W}_{t}}\right) \text { at date } \mathrm{t}+1
$$

\footnotetext{
${ }^{3}$ The "national average wage index" computed by Social Security is actually a measure of average income for covered workers. As such, it is comparable to a measure of average per capita labor income, not an average wage rate.
} 


$$
\begin{gathered}
\$ 1\left(\frac{\bar{W}_{t+1}}{\bar{W}_{t}}\right)\left(\frac{\bar{W}_{t+2}}{\bar{W}_{t+1}}\right) \text { at date } \mathrm{t}+2 \\
\$ 1\left(\frac{\bar{W}_{t+1}}{\bar{W}_{t}}\right)\left(\frac{\bar{W}_{t+2}}{\bar{W}_{t+1}}\right) \cdots\left(\frac{\bar{W}_{t+R}}{\bar{W}_{t+R-1}}\right) \text { at the retirement date, } \mathrm{t}+\mathrm{R} .
\end{gathered}
$$

Equation (2) shows that the nominal return during the accumulation phase to $\$ 1$ 'invested' in Social Security is the growth rate of the wage indexing series, since this is the amount by which the $\$ 1$ is 'marked up' each period up to the retirement date. Let's use the notation $r_{t+1}^{S S}$ to stand for the return on the Social Security asset between periods $t$ and $t+1$ :

$$
r_{t+1}^{S S} \equiv \frac{\bar{W}_{t+1}-\bar{W}_{t}}{\bar{W}_{t}}
$$

Using this notation, $\$ 1$ at date t grows to:

$$
\$ 1\left(1+r_{t+1}^{S S}\right)\left(1+r_{t+2}^{S S}\right) \ldots\left(1+r_{t+R}^{S S}\right) \text { at the retirement date, } \mathrm{t}+\mathrm{R} .
$$

The worker's average indexed monthly earnings is then the average over the individual's working life of $W_{t+j}^{\text {indexed }}:^{4}$

$$
\begin{aligned}
A I M E & =\frac{1}{12}\left[\frac{1}{R+1} \sum_{j=0}^{R} W_{t+j}\left(\frac{\bar{W}_{t+R}}{\bar{W}_{t+j}}\right)\right] \\
& =\frac{1}{12}\left[\frac{1}{R+1}\left(\sum_{j=0}^{R}\left[W_{t+j}\left(\Pi_{k=1}^{R-j}\left(1+r_{t+j+k}^{S S}\right)\right)\right]+W_{t+R}\right)\right] .
\end{aligned}
$$

The individual's Social Security benefit during retirement is a concave function of the individual's AIME. Specifically, the individual's "Primary Insurance Amount," PIA, equals $90 \%$ of the first $\$ 477$ of AIME plus $32 \%$ of AIME over $\$ 477$ through $\$ 2,875$ plus $15 \%$ of AIME over $\$ 2875$. Through eq. (4) it is evident that the Social Security benefit depends on the rate of return on the Social Security asset during the accumulation phase.

To learn more about the properties of the Social Security asset, Figure 1 plots the growth rates of nominal GNP, per capital nominal labor income, and the Social Security Wage Index. As is evident from the figure, and can be seen in detail in

\footnotetext{
${ }^{4}$ The AIME calculation may exclude some low-wage years and years of non-employment-a feature not captured by our formula.
} 
Figure 1: Growth rates of GNP, labor income, and SSWI

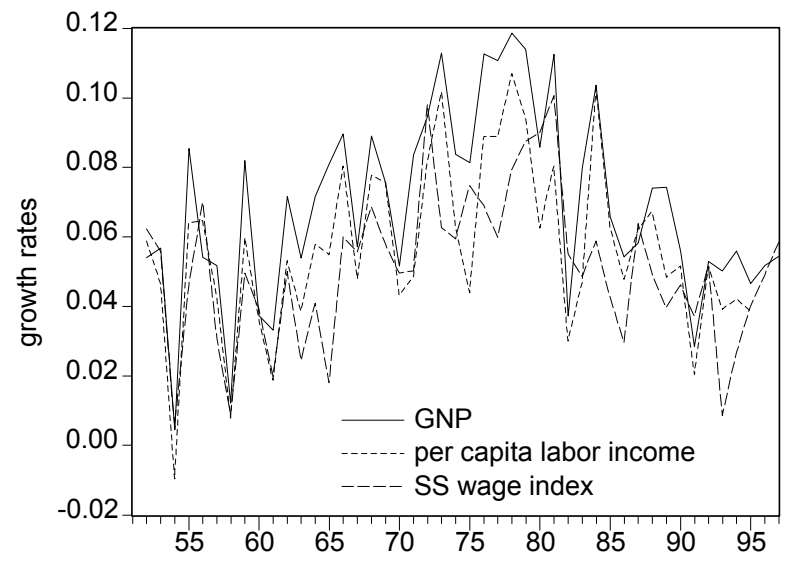

Table 4, these series are highly correlated with each other, and display similar levels of volatility. Specifically, the mean growth rate for nominal GNP was $6.95 \%$ per year over the period the 1951-1996 period, while per capita income grew at $5.66 \%$ per year and the SSWI grew at $5.10 \%$ per year. GNP growth was somewhat more volatile than labor income growth or SSWI growth: (GNP growth had a standard deviation of $2.73 \%$ per year compared with $2.46 \%$ per year for labor income growth and $2.23 \%$ per year for SSWI growth). The correlation between GNP growth and per capita labor income growth was 0.92 , whereas SSWI growth had a correlation of only 0.71 with GNP growth and 0.72 with per capita labor income growth.

\section{Human capital and Social Security: An illus- trative model}

This section presents a model of the link between Social Security returns and human capital returns during an individual's working lifetime. To simplify the present value calculations, we will assume that an individual lives forever. The period- $t$ value of a individual's human capital, $H_{t}$ is the present discounted value of current and future labor income, $Y_{t}$, where we assume that the discount factor, $\rho$, is time-invariant:

$$
H_{t}=\sum_{j=0}^{\infty} \rho^{j} E_{t} Y_{t+j} .
$$


To proceed, we must specify the statistical process for labor income and its relationship to the SSWI. We assume that the SSWI is a random walk, so that

$$
S S W I_{t}=\alpha_{S S W I}+S S W I_{t-1}+\varepsilon_{t}
$$

where $\varepsilon_{t} \sim$ i.i.d. $N\left(0, \sigma_{\varepsilon}^{2}\right)$.

An individual's labor income, $Y_{t}$, may depend on aggregate economic activity as well as individual-specific factors. We let the aggregate factor be the SSWI, which we have seen is strongly correlated with GNP and with the national accounts' measure of aggregate labor income. Letting $X_{t}$ denote the individual-specific variables, we specify that:

$$
Y_{t}=\alpha_{Y}+\beta\left(S S W I_{t}\right)+\gamma X_{t}+u_{t}
$$

where $u_{t} \sim$ i.i.d. $N\left(0, \sigma_{u}^{2}\right)$. To simplify the analysis, suppose that $X_{t}$ is a single variable and is also a random walk, so that

$$
X_{t}=\alpha_{X}+X_{t-1}+\nu_{t}
$$

The change in the expected value of period- $t$ human capital will then be given by:

$$
H_{t}-E_{t-1} H_{t}=\sum_{j=0}^{\infty} \rho^{j}\left(E_{t} Y_{t+j}-E_{t-1} Y_{t+j}\right) .
$$

Substituting from (6)-(8), we have:

$$
H_{t}-E_{t-1} H_{t}=\left(\frac{\beta}{1-\rho}\right) \varepsilon_{t}+\left(\frac{\gamma}{1-\rho}\right) \nu_{t}+u_{t} .
$$

Equation (9) illustrates that effect of innovations in the permanent and temporary components of income on the revision in the valuation of human capital. Recall that $\varepsilon_{t}$ is the innovation in the stochastic trend that is identified with SSWI; $\nu_{t}$ is the innovation in the individual-specific stochastic trend; and $u_{t}$ is the temporary, individual-specific disturbance to income.

Innovations in the stochastic trends dominate the revision in the valuation of human capital. For example, if an individual has a discount factor of $\rho=0.95$, and has $\beta=1$ (which would be the average beta for all working individuals, as long as the SSWI is exactly the same thing as average per capita labor income), then a $1 \%$ increase in $S S W I_{t}\left(\varepsilon_{t}=0.01\right)$ will lead to a $20 \%$ upward revision in the individual's valuation of his human capital $(1 /(1-0.95)=0.20)$. Even if an individual had a 
low value of $\beta$, say $\beta=0.30$, a $1 \%$ increase in $S S W I_{t}$ would lead to a $6 \%$ upward revision in the valuation of human capital $(0.30 /(1-0.95)=0.06)$. By contrast, a $1 \%$ increase in the transitory component of income, $u_{t}=0.01$, will lead to only a $1 \%$ increase in the value of human capital.

This analysis shows that the permanent components of income changes will dominate revisions in the valuation of human capital; this will be true even if these permanent components explain, in a $R^{2}$ sense, very little of the time-series variation in income. To see this, imagine running a regression based on the first-difference of equation (7):

$$
\Delta Y_{t}=k+\beta\left(\Delta S S W I_{t}\right)+\gamma \Delta X_{t}+\Delta u_{t}
$$

where the operator $\Delta$ indicates the first-difference in the levels of a variable, e.g., $\Delta Y_{t} \equiv Y_{t}-Y_{t-1} .^{5} \quad$ The $R^{2}$ from the regression (10) would then be:

$$
R^{2}=\frac{\beta^{2} \sigma_{\varepsilon}^{2}+\gamma^{2} \sigma_{\nu}^{2}}{\beta^{2} \sigma_{\varepsilon}^{2}+\gamma^{2} \sigma_{\nu}^{2}+2 \sigma_{u}^{2}} .
$$

For many individuals, income fluctuations may be dominated by individual-specific, temporary influences. That is: $2 \sigma_{u}^{2}$ may be much larger than $\left(\beta^{2} \sigma_{\varepsilon}^{2}+\gamma^{2} \sigma_{\nu}^{2}\right)$, leading to a low $R^{2}$. Yet the revisions in the value of human capital will still be dominated by innovations in the trend components of income, since only these components have a persistent effect on future income. The returns on an individual's human capital will be strongly related to the returns on SSWI if the dominant trend in an individual's income is the trend that is shared with the SSWI. The next section provides empirical evidence on this point.

\section{Empirical evidence}

This section presents empirical evidence on the time series behavior of labor income for various socio-economic groups, and documents the extent to which labor income is related to changes in the SSWI. The section begins with an informal look at the data, and then proceeds to estimation of group-level regressions of income growth on the SSWI.

\footnotetext{
${ }^{5}$ The estimation of the income regressions carried out in Section 5 will use a differenced version of the income equation because we do not have data on the individual-specific variables, $X$. With data on $X$, estimation in levels would be preferred; without data on $X$, potential problems with spurious regression means that estimation in differences is preferred.
} 


\subsection{Labor income and the SSWI: A first look}

A typical individual's labor income is much more volatile than the SSWI; this was illustrated in Table 4. Yet the extent to which Social Security represents a security with returns that are highly correlated with those of human capital depends on subtler issues, which we explore in this section.

The most important determinant of the correlation of the returns between Social Security and human capital is the relationship between the trends in the SSWI and the individual's labor income. To gain an idea of these trends, Figure 2-A plots the SSWI together with labor income for the 9 individuals in the first socioeconomic group reported in Table 2: married white females with less than a high school education and age $<46$ at the end of the sample period. This figure suggests that there is little relationship between the trend behavior of the SSWI and the trend behavior of income for individuals in this group; indeed, there does not seem to be any trend at all in group income.

Figure 2-B plots the SSWI together with labor income for the first 15 individuals in our sample from the group of married white females with more than a high school education, and aged 46-55 years at the end of the sample period (there are 69 such individuals in the sample). In contrast to Figure 2-A, there does appear to be a definite trend to income within this group, which might possibly be similar to the trend in the SSWI. To explore this possibility, Figure 2-C plots income divided by the SSWI for the same 15 individuals. The resulting variables appear to have much less pronounced trends, and for many individuals it seems that a null hypothesis of stationarity in this variable might not be rejected. In any case, normalizing the SSWI appears to account for most of the trend in income for most individuals in this category.

\subsection{Specification of individual-level regressions}

Following eq. (13), we specify the change in the SSWI as a random walk, possibly with drift, and also allowing the possibility of a deterministic, as well as a stochastic trend, as follows:

$$
\begin{gathered}
S S W I_{t}=\alpha_{S S W I}+\mu_{S S W I} t+S S W I_{t-1}+\varepsilon_{t} \\
\Delta S S W I_{t}=\mu_{S S W I}+\varepsilon_{t} .
\end{gathered}
$$


where $\varepsilon_{t} \sim$ i.i.d. $N\left(0, \sigma_{\varepsilon}^{2}\right)$. We modify eq. (7), to include a possible time trend, and we specify that the change in an individual's labor income depends on $S S W I_{t}$, with a coefficient that depends on the individual's socioeconomic group. :

$$
Y_{i j t}=\alpha_{i j}+\mu_{Y_{i j}} t+\beta_{j} S S W I_{t}+\gamma_{i j} X_{i j t}+u_{i j t}
$$

where $u_{i j t} \sim$ i.i.d. $N\left(0, \sigma_{u_{i j}}^{2}\right)$. Finally, we modify the process for the individualspecific variables to allow a time trend:

$$
X_{i j t}=\alpha_{X_{i j}}+\mu_{X i j} t+X_{i j, t-1}+\nu_{i j t}
$$

with $\nu_{i j t} \sim i . i . d . \quad N\left(0, \sigma_{\nu_{i j}}^{2}\right)$. We will further assume that there is no correlation between aggregate influences on the individual's wage, as reflected in $S S W I_{t}$, and the individual-specific influences captured in $X_{i j t}$.

Because of the potential presence of stochastic trends combined with the unavailability of data on $X_{i j t}$, equation (14) was estimated in the following form, where the $\Delta$ operator indicates the change in the level of a variable, e.g., $\Delta S S W I_{t}=$ $S S W I_{t}-S S W I_{t-1}$ :

$$
\Delta Y_{i j t}=\left(\mu_{Y_{i j}}+\gamma_{i j} \mu_{X_{i j}}\right)+\beta_{j} \Delta S S W I_{t}+\zeta_{i j t},
$$

where $\zeta_{i j t} \equiv \gamma_{i j}\left(\Delta X_{i j t}-\mu_{X_{i j}}\right)+\left(u_{i j t}-u_{i j, t-1}\right)$.

\subsection{Results}

The results from the estimation of (15) are presented in Table 5. For each socioeconomic group, the table reports the estimate of $\beta_{j}$ and the standard error of the estimate, and the $R^{2}$ of the regression. ${ }^{6}$ Since our specification of the income process assumes that the coefficient on $\Delta S S W I_{t}$ depends on the group but not on individual characteristics, it may be of interest to know how much explanatory power there is in a regression of the change in group mean income, $\Delta \bar{Y}_{j t}$, on $\Delta S S W I_{t}$ :

$$
\Delta \bar{Y}_{j t}=\alpha_{j}+\beta_{j} \Delta S S W I_{t}+\zeta_{j t}
$$

The $R^{2}$ from this regression is reported as the last column in Table 5.

\footnotetext{
${ }^{6}$ The standard error for beta is not corrected for heteroscedasticity; this will be computed in a future draft of the paper.
} 
Table 5 shows that there are important differences across groups in the sensitivity of income growth to changes in the SSWI; there are also important differences in the extent to which growth in the SSWI explains income growth. Those groups that have the highest estimates of $\beta_{j}$ are white females, especially those with at least a high school education, and especially those who are in the middle age group (46-55 years) at the end of the sample. For example, the estimate of $\beta_{j}$ is 1.73 (s.e. $=0.35$ ) for married white females with more than a high school education and age between 46-55 years. The corresponding number for single females with otherwise the same characteristics is $\widehat{\beta}_{j}=0.97$ (s.e. $=0.18$ ). There are many other instances of large positive estimates of $\beta_{j}$ within the white female subgroups. By contrast, black females tend not to have large estimates of $\beta_{j}$ : the exceptions are in those categories described above: individuals with more education and who are at least 46 years old at the end of the sample period. For example, married black females with more than a high school education have estimates of $\beta_{j}$ equal to 0.47 (the age $46-55$ group) and 1.20 (the age 56-65 group). The sample sizes are small within this group, and the estimated standard errors are large, so it is less clear that there is a strong positive dependence of income growth on SSWI growth for these groups. Table 5 also reports estimates of $\beta$ for larger groups, e.g., all married white females taken together, with a single $\beta_{j}$ estimated for the group. These results confirm the earlier impression that there is a strong, positive, and significant relationship between income growth and SSWI growth for white women, both married and single, but not for black women.

Turning to the results for men, we find that here is very little evidence that income growth for men is systematically related to changes in the SSWI. This is surprising, since men are a larger share of the labor force; they account for most of labor income; and are more likely to be continuously employed than are females. Since the SSWI is a measure of aggregate labor income, it would have been natural to expect a strong, significant relationship in the mens' regressions. While there are positive coefficient estimates in some cases, notably for the more-educated white men (in parallel with the results for women), there is not the same strong systematic relationship that we observed for women. This is reflected in the group estimates for $\beta_{j}$, which are all small and insignificant (with the exception of the Single Black Male category, which contains only 1 individual).

There are also important differences across socioeconomic groups in terms of the explanatory power of SSWI growth for income growth. For the individual-level 
regressions for women (estimation of (15)), the $R^{2}$ s range from 0.00 to about 0.20 . Further, some of the largest values of the $R^{2}$ correspond to those cases for which the estimated $\beta_{j}$ are large and significant: specifically, women with at least a high school education. The explanatory power of the individual regressions for men is much lower. Finally, the last column of Table 3 presents the $R^{2}$ for the group regression, eq. (16). There is a great deal of heterogeneity across groups in the extent to which SSWI changes can explain changes in group income, but once again the highest $R^{2} s$ occur for regressions of women's income, especially white women. For example, SSWI growth explains $83 \%$ of mean income growth for married white women with more than a high school education and ages 46-55. SSWI growth explains $80 \%$ of mean income growth for married white women, $50 \%$ of income growth for single white women, $58 \%$ of income growth for married black females, but only $25 \%$ of income growth for single black females. The results for the men show that the explanatory power of SSWI changes is lower than for the corresponding category for women (e.g., SSWI growth explains only $39 \%$ of income growth for married white males, compared with $80 \%$ for married white females). Further, there are only a few sub-categories for which there is a large group $R^{2}$ : most of these are sub-categories of married white males.

Table 6 recomputes estimation of group-level $\beta$ coefficients using data on all individuals who had some labor income during the sample period, i.e., not excluding those individuals who had a change in marital status during the sample period. ${ }^{7}$ On the whole, the results from Table 6 reinforce the main impression gained from Table 5: women's labor income tends to have a component that is closely related to movements in the SSWI, while men's labor income appears largely unrelated to the SSWI. Labor income growth for white women, taken as a group, is strongly related to the SSWI, with an estimated $\widehat{\beta}=0.62$ with a standard error of 0.13 . By contrast, the $\beta$ for black women is only $\widehat{\beta}=0.06$. The estimate of $\beta$ rises with educational attainment, from a low of $\beta=-0.03$ (s.e. $=0.17)$ for women with less than a high school education, to $\widehat{\beta}=0.99$ (s.e. $=0.22)$ for women with more than a high school education. The link between the SSWI and labor income is also stronger for younger women: the group with age less than 46 years at the end of sample has $\widehat{\beta}=1.01$ $($ s.e. $=0.28)$; the group aged $46-55$ years has $\widehat{\beta}=0.71$ (s.e. $=0.15$ ), while the group

\footnotetext{
${ }^{7}$ This increases the number of women in the sample from 575 to 1012, and increases the number of men in the sample from 509 to 632 .
} 
that is near retirement at the end of sample, ages 56-65 years, has a low estimate of $\widehat{\beta}=0.12$ (s.e. $=0.21$ ).

By contrast, there are few sub-groups of men for which there is a positive, significant relationship between labor income growth and SSWI growth. In fact, there are only a few positive estimates of $\beta$. These groups are men with more than a high school education, with $\beta=0.47$; those with ages less than 46 years at the end of the sample period $(\beta=0.56)$, and those aged $46-55$ years $(\beta=0.70)$. However, the estimated standard errors of these estimates are much larger than for the corresponding women's groups, so that the estimated $\beta$ coefficients cannot be viewed as significantly different from zero for any of the sub-groups.

The bottom panel of Table 6 computes estimates by sub-group when men and women are taken together. Given the disparity between the results for women's sub-groups and men's sub-groups, these results should be taken with a grain of salt. That said, the impression from this combined sample is that the groups with the highest sensitivity to SSWI growth are groups of individuals with more education and young-to-middle-aged individuals.

\section{Benefits from Social Security reform}

The empirical results of the preceding sub-sections suggest that there are important differences across socio-economic groups in the sensitivity of labor income growth to changes in the SSWI. Labor income growth is approximately the rate of return on human capital, and because changes in the SSWI are related to the return on Social Security during the accumulation phase (i.e., during an individual's working life). Since human capital and Social Security represent two important, non-traded assets for an individual, a positive covariance between the returns on these assets is undesirable. To see why, consider the following. Suppose an individual experiences a period of low growth of labor income. If this individual has a large $\beta$ on SSWI growth, then the period of low growth of labor income is likely to correspond to a period in which the Social Security return is low, i.e., the individual's contributions to Social Security will be marked up by a low percentage amount. That is: a period in which low income means a reduced ability to consume in the present and save for the future corresponds to a period in which the value of the Social Security asset also grows by a small amount. 
In fact, things can be much worse than this. The illustrative model of Section 4 and the informal empirical analysis of Section 5 suggested that labor income growth and SSWI growth likely share a stochastic trend: if so, this stochastic trend will likely dominate human capital returns. In this case, a negative innovation in this stochastic trend corresponds to a large, negative shock to the value of an individual's human capital (with a corresponding negative impact on current and future consumption) and at the same time corresponds to a large, negative shock to the expected future value of the Social Security asset, thus reducing expected future consumption from this source.

The first lesson of portfolio theory is that individual's should hold diversified portfolios, so that negative returns on one asset will tend to be offset by positive returns on other assets. But in the scenario just sketched out, the individual has a portfolio of assets-human capital and Social Security-with highly correlated returns. What can be done to improve this situation?

Ideally, the individual would like to trade in financial assets that have returns highly correlated with the returns on these nontraded assets. In Section 3, we saw that returns on the SSWI are highly correlated with the growth rates of GNP and aggregate labor income. "Macro markets" of the type advocated by Robert Shiller (1993) would be useful as hedging vehicles for the risk associated with the traditional Social Security system. Specifically, an individual could sell claims on a "GNP index" in an amount equal to his or her Social Security contributions, and could use the proceeds to purchase other financial assets that were less highly correlated with his/her nontraded human capital. In fact, the individual would ideally like to hedge that component of labor income risk associated with aggregate risk (captured in the model of Section 4 by the term $\gamma_{j} S S W I_{t}$ in eq. (7)).

Absent the creation of these macro markets, individuals could still benefit from Social Security reform that would allow the individual to choose the financial assets in which contributions during the working lifetime would be invested. Individuals would no longer be able to create hedges for Social Security risk, but at least they could invest their Social Security 'contributions' in assets whose returns were less highly correlated with the returns on nontraded human capital. Our results for disaggregated socio-economic groups suggest that women have the most to gain from this type of Social Security reform, since the evidence shows that women's labor income growth is most closely related to changes in the SSWI. By contrast, men's 
labor income growth appears largely unrelated to SSWI growth, suggesting that men may have less to gain from Social Security reform that permits investment in a broader range of assets.

\section{References}

[1] Baxter, Marianne and Robert G. King (1999) The Role of International Investment in a Privatized Social Security System" (with R. King), forthcoming in Risk Aspects of Investment Based Social Security Reform (M. Feldstein and J. Campbell, eds.,), University of Chicago Press.

[2] Gustman, Alan; Olivia Mitchell, Andrew Samwick, and Thomas Steinmeier (1997) "Pension and Social Security Wealth in the Health and Retirement Study," National Bureau of Economic Research Working Paper No. 5912, February 1997.

[3] Gustman, Alan and Thomas Steinmeier (1998) "Effects Of Pensions On Savings: Analysis With Data From The Health and Retirement Study" NBER working paper no. 6681, Aug 1998.

[4] Kennickell, Arthur; Martha Starr-McCluer, and Annika Sunden (1997) "Family Finances in the U.S.: Recent Evidence from the Survey of Consumer Finances,"Board of Governors of the Federal Reserve System, Federal Reserve Bulletin, January 1997.

[5] Shiller, Robert J., Macro Markets: Creating institutions for managing society's largest economic risks, Clarendon Lectures in Economics. Oxford and New York: Oxford University Press, Clarendon Press, 1993. 
Table 1: Social Security as a Fraction of Retirement Wealth

\begin{tabular}{|c|c|c|c|c|c|c|c|c|c|c|}
\hline & & & & time Ear & lings Perc & entile -- Al & householc & & & \\
\hline & $0-5$ & $5-10$ & $10-25$ & 25-50 & $50-75$ & $75-90$ & $90-95$ & $95-100$ & 45-55 & All \\
\hline Social Security value & 6,230 & 30,829 & 61,555 & 104,097 & 145,690 & 167,239 & 177,754 & 179,164 & 128,866 & 116,455 \\
\hline Other assets: total & 57,204 & 103,225 & 113,852 & 243,822 & 376,769 & 568,097 & 772,415 & $1,431,528$ & 382,344 & 375,365 \\
\hline House value & 24,692 & 45,612 & 40,021 & 60,760 & 81,026 & 106,617 & 134,078 & 222,910 & 72,914 & 78,826 \\
\hline Real estate value & 4,793 & 12,836 & 15,844 & 30,293 & 34,052 & 54,509 & 66,207 & 167,714 & 37,126 & 39,227 \\
\hline Business assets & 2,799 & 7,947 & 7,409 & 25,665 & 35,513 & 41,809 & 106,917 & 223,031 & 36,056 & 39,724 \\
\hline Financial assets & 14,165 & 15,746 & 11,634 & 23,819 & 35,612 & 66,931 & 77,528 & 202,297 & 25,972 & 42,140 \\
\hline IRA assets & 3,158 & 4,012 & 5,307 & 9,699 & 17,188 & 35,544 & 53,765 & 79,254 & 13,192 & 19,613 \\
\hline Pension value & 1,018 & 7,002 & 21,668 & 70,140 & 138,436 & 216,857 & 289,104 & 443,382 & 93,930 & 124,991 \\
\hline Health insurance value & 209 & 1,109 & 3,002 & 6,469 & 11,315 & 16,141 & 13,641 & 10,860 & 80,212 & 8,461 \\
\hline Other & 6,370 & 8,961 & 8,967 & 16,977 & 23,627 & 29,689 & 31,175 & 82,080 & 22,942 & 22,383 \\
\hline $\begin{array}{l}\text { Social Security as a fracti } \\
\text { of total retirement assets }\end{array}$ & 0.10 & 0.23 & 0.35 & 0.30 & 0.28 & 0.23 & 0.19 & 0.11 & 0.25 & 0.24 \\
\hline $\begin{array}{l}\text { Social Security as a fracti } \\
\text { of liquid assets at } \\
\text { retirement }\end{array}$ & 0.25 & 0.54 & 0.61 & 0.50 & 0.43 & 0.34 & 0.30 & 0.20 & 0.49 & 0.38 \\
\hline Average Lifetime Earnings & 27,273 & 144,854 & 392,781 & 844,443 & $1,345,378$ & $1,886,986$ & $2,470,710$ & $5,048,032$ & $1,098,095$ & $1,273,960$ \\
\hline
\end{tabular}

Notes:

1. All data from Gustman, et al. (1997) and Gustman and Steinmeier (1998).

2. Liquid assets include Social Security, financial assets, IRA assets, and pension value. 
Table 2: Human capital and net worth

\begin{tabular}{|c|c|c|c|c|c|c|}
\hline & $\begin{array}{c}\begin{array}{c}\text { Future } \\
\text { years of } \\
\text { work }\end{array} \\
\end{array}$ & $\begin{array}{c}\text { median } \\
1995 \\
\text { income } \\
\end{array}$ & $\begin{array}{c}\text { median } \\
1995 \text { net } \\
\text { worth } \\
\end{array}$ & $\begin{array}{c}1995 \\
\text { income } \\
\text { / net } \\
\text { worth } \\
\end{array}$ & 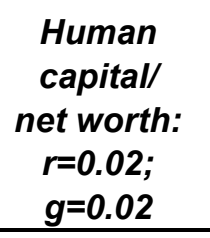 & $\begin{array}{c}\text { Human } \\
\text { capital/ } \\
\text { net worth: } \\
r=0.08 ; \\
g=0.02\end{array}$ \\
\hline \multicolumn{7}{|l|}{ income group } \\
\hline less than 10,000 & 23 & 5,000 & 4,800 & 1.0 & 23.5 & 12.7 \\
\hline $10,000-24,999$ & 23 & 17,500 & 30,000 & 0.6 & 13.2 & 7.1 \\
\hline $25,000-49,999$ & 23 & 37,500 & 54,900 & 0.7 & 15.4 & 8.3 \\
\hline $50,000-99,999$ & 23 & 75,000 & 121,100 & 0.6 & 14.0 & 7.5 \\
\hline 100,000 and more & 23 & 200,000 & 485,900 & 0.4 & 9.3 & 5.0 \\
\hline \multicolumn{7}{|l|}{ Age of head } \\
\hline Less than 35 & 37 & 26,700 & 11,400 & 2.3 & 85.0 & 34.3 \\
\hline $35-44$ & 25 & 39,100 & 48,500 & 0.8 & 19.8 & 10.2 \\
\hline $45-54$ & 15 & 41,100 & 90,500 & 0.5 & 6.7 & 4.4 \\
\hline $55-65$ & 5 & 36,000 & 110,800 & 0.3 & 1.6 & 1.3 \\
\hline $65-74$ & 1 & 19,500 & 104,100 & 0.2 & 0.2 & 0.2 \\
\hline 75 and more & 0 & 17,300 & 95,100 & 0.2 & 0.0 & 0.0 \\
\hline \multicolumn{7}{|l|}{ Education of head } \\
\hline No high school diploma & 23 & 15,700 & 26,300 & 0.6 & 13.5 & 7.3 \\
\hline High school diploma & 23 & 26,700 & 50,000 & 0.5 & 12.0 & 6.5 \\
\hline Some college & 23 & 29,800 & 43,200 & 0.7 & 15.6 & 8.4 \\
\hline College degree & 23 & 46,300 & 104,100 & 0.4 & 10.0 & 5.4 \\
\hline \multicolumn{7}{|l|}{ Race or ethnicity of head } \\
\hline White non-hispanic & 23 & 48,600 & 73,900 & 0.7 & 14.8 & 8.0 \\
\hline Nonwhite or hispanic & 23 & 29,500 & 16,500 & 1.8 & 40.3 & 21.8 \\
\hline \multicolumn{7}{|l|}{ Current work status of head } \\
\hline Professional, managerial & 23 & 72,700 & 89,300 & 0.8 & 18.4 & 9.9 \\
\hline Technical, sales, clerical & 23 & 46,200 & 43,300 & 1.1 & 24.1 & 13.0 \\
\hline Precision production & 23 & 43,800 & 43,500 & 1.0 & 22.7 & 12.3 \\
\hline Machine operators and labo & 23 & 35,600 & 37,300 & 1.0 & 21.5 & 11.6 \\
\hline Service occupations & 23 & 27,200 & 15,800 & 1.7 & 38.8 & 21.0 \\
\hline Self-employed & 23 & 79,000 & 152,900 & 0.5 & 11.7 & 6.3 \\
\hline Retired & 0 & 27,300 & 81,600 & 0.3 & 0.0 & 0.0 \\
\hline Other not working & 23 & 19,900 & 4,500 & 4.4 & 99.7 & 53.9 \\
\hline
\end{tabular}

\section{Notes:}

1. All data from 1995 Survey of Consumer Finances, as summarized in Kennickell, et al. (1997).

2. Number of years of remaining working life generally assumed to be 23 years (midpoint of working from age 20 to age 65). In the case of age groups, the number of years for an individual at the midpoint of the age group is used.

3. Median income for the " income group" breakdown is the midpoint of the range, except for the highest group (more than $\$ 100,000$ ) where we have arbitrarily used the figure $\$ 200,000$ as the median.

4. To calculate the ratio of the value of human capital to net worth, we capitalized current income over the individual's remaining working life assuming that income rises at the rate $g$ and using a discount rate of $r$. This calculation assumes that current income consists of wage income only, which may not be a good assumption for higher-income individuals. However, this error will bias upward the human capital/net worth ratio for individuals with high net worth and thus high non-wage income, thus reducing the disparity between high- and low-wage groups. 
Table 3: Summary statistics for income

\# of ind's. mean level of

Education Age group in group income $(Y)$

Married white females

roup

$\begin{array}{cc}<\mathrm{HS} & <46 \\ <\mathrm{HS} & 46-55 \\ <\mathrm{HS} & 56-65 \\ =\mathrm{HS} & <46 \\ =\mathrm{HS} & 46-55 \\ =\mathrm{HS} & 56-65 \\ >\mathrm{HS} & <46 \\ >\mathrm{HS} & 46-55 \\ >\mathrm{HS} & 56-65\end{array}$

All members of group:

110

9

38

52

14

83

110

12

69

58

445

$\$ 2,014$

3,543

3,148

5,044

4,926

4,557

7,241

8,757

7,197

$\$ 5,406$

\section{Single white females}

$\begin{array}{lc}<\mathrm{HS} & <46 \\ <\mathrm{HS} & 46-55 \\ <\mathrm{HS} & 56-65 \\ =\mathrm{HS} & <46 \\ =\mathrm{HS} & 46-55 \\ =\mathrm{HS} & 56-65 \\ >\mathrm{HS} & <46 \\ >\mathrm{HS} & 46-55 \\ >\mathrm{HS} & 56-65\end{array}$

All members of group:

Married black females

$\begin{array}{cc}<\mathrm{HS} & <46 \\ <\mathrm{HS} & 46-55 \\ <\mathrm{HS} & 56-65 \\ =\mathrm{HS} & <46 \\ =\mathrm{HS} & 46-55 \\ =\mathrm{HS} & 56-65 \\ >\mathrm{HS} & <46 \\ >\mathrm{HS} & 46-55 \\ >\mathrm{HS} & 56-65\end{array}$

All members of group:

\section{Single black females}

$\begin{array}{cc}<\mathrm{HS} & <46 \\ <\mathrm{HS} & 46-55 \\ <\mathrm{HS} & 56-65 \\ =\mathrm{HS} & <46 \\ =\mathrm{HS} & 46-55 \\ =\mathrm{HS} & 56-65 \\ >\mathrm{HS} & <46 \\ >\mathrm{HS} & 46-55 \\ >\mathrm{HS} & 56-65\end{array}$

All members of group:

$\begin{array}{rrr}N A & N A & N A \\ N A & N A & N A \\ N A & N A & N A \\ \$ 9,184 & \$ 816 & \$ 3,895 \\ 12,529 & 1,081 & 2,518 \\ 14,332 & 331 & 3,852 \\ 13,265 & 873 & 2,259 \\ 16,878 & 1,227 & 2,587 \\ 14,695 & 523 & 4,863 \\ \$ 14,677 & \$ 853 & \$ 3,388 \\ & & \\ & & \\ \$ 5,519 & \$ 328 & 2,796 \\ 3,362 & 228 & 2,056 \\ 2,846 & 89 & 1,895 \\ 11,478 & 861 & 3,296 \\ 6,806 & 530 & 2,288 \\ 5,313 & 353 & 2,441 \\ 6,048 & 614 & 2,402 \\ 7,412 & 525 & 2,442 \\ 6,394 & 434 & 2,427 \\ \$ 4,666 & \$ 299 & \$ 2,201\end{array}$

NA
$\$ 6,970$

NA

$\$ 704$

237

NA

418

NA

NA

592

NA

$\$ 480$ std dev of $\Delta Y$

$\$ 3,013$

2,243

1,548

3,302

2,233

2,082

2,981

3,357

4,198

$\$ 2,616$

3,895

3,852

2,259

2,587

4,863

$\$ 3,388$

$\$ 2,796$

2,056

1,895

3,296

2,288

2,402

2,442

2,427

2,201

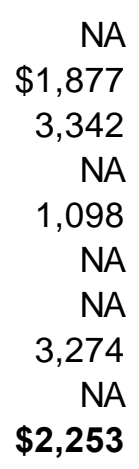


\# of ind's. mean level of

Education Age group in group income $(\mathrm{Y})$

Married white males

$\begin{array}{lc}<\mathrm{HS} & <46 \\ <\mathrm{HS} & 46-55 \\ <\mathrm{HS} & 56-65 \\ =\mathrm{HS} & <46 \\ =\mathrm{HS} & 46-55 \\ =\mathrm{HS} & 56-65 \\ >\mathrm{HS} & <46 \\ >\mathrm{HS} & 46-55 \\ >\mathrm{HS} & 56-65\end{array}$

All members of group:

$\begin{array}{rr}4 & \$ 10,206 \\ 37 & 14,447 \\ 72 & 14,534 \\ 5 & 17,603 \\ 45 & 21,100 \\ 74 & 17,562 \\ 6 & 19,968 \\ 68 & 27,793 \\ 96 & 26,723\end{array}$

mean $\Delta \mathrm{Y}$

std dev of $\Delta Y$

$\$ 20,968$

$\$ 644$

656

317

939

1,146

299

1,189

1,713

796

$\$ 806$
$\$ 8,110$

4,486

5,209

6,976

6,429

6,421

6,615

7,524

9,343

$\$ 6,931$

\section{Single white males}

$\begin{array}{lc}<\mathrm{HS} & <46 \\ <\mathrm{HS} & 46-55 \\ <\mathrm{HS} & 56-65 \\ =\mathrm{HS} & <46 \\ =\mathrm{HS} & 46-55 \\ =\mathrm{HS} & 56-65 \\ >\mathrm{HS} & <46 \\ >\mathrm{HS} & 46-55 \\ >\mathrm{HS} & 56-65\end{array}$

All members of group:

\section{Married black males}

$\begin{array}{lc}<\mathrm{HS} & <46 \\ <\mathrm{HS} & 46-55 \\ <\mathrm{HS} & 56-65 \\ =\mathrm{HS} & <46 \\ =\mathrm{HS} & 46-55 \\ =\mathrm{HS} & 56-65 \\ >\mathrm{HS} & <46 \\ >\mathrm{HS} & 46-55 \\ >\mathrm{HS} & 56-65\end{array}$

All members of group:

\section{Single black males}

All members of group:

\begin{tabular}{|c|c|}
\hline$<\mathrm{HS}$ & $<46$ \\
\hline$<\mathrm{HS}$ & $46-55$ \\
\hline$<\mathrm{HS}$ & $56-65$ \\
\hline$=\mathrm{HS}$ & $<46$ \\
\hline$=\mathrm{HS}$ & $46-55$ \\
\hline$=\mathrm{HS}$ & $56-65$ \\
\hline$>\mathrm{HS}$ & $<46$ \\
\hline$>\mathrm{HS}$ & $46-55$ \\
\hline$>\mathrm{HS}$ & $56-65$ \\
\hline
\end{tabular}

1
13
47
2
13
10
0
5
4

95

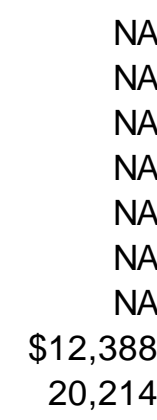

$\$ 14,997$

$\begin{array}{rr}N A & N A \\ N A & N A \\ N A & N A \\ N A & N A \\ N A & N A \\ N A & N A \\ N A & N A \\ \$ 822 & \$ 4,372 \\ 943 & 2,951 \\ \$ 862 & \$ 3,898\end{array}$

$\$ 665$

$\$ 4,337$

4,731

3,981

5,837

4,462

5,171

NA

4,697

6,906

21,204

$\$ 12,973$

$\$ 4,478$

$\$ 490$

$\begin{array}{lrrr}0 & N A & N A & \text { NA } \\ 0 & N A & N A & \text { NA } \\ 0 & N A & N A & \text { NA } \\ 0 & N A & N A & \text { NA } \\ 0 & N A & N A & \text { NA } \\ 0 & N A & N A & \text { NA } \\ 0 & N A & N A & \text { NA } \\ 1 & \$ 14,847 & \$ 905 & \$ 1,044 \\ 0 & 0 & 0 & 0 \\ 1 & \$ 14,847 & \$ 905 & \$ 1,044 \\ & & & \$ 262\end{array}$

Note: The standard deviation of income changes was computed by first calculating the standard deviation of income changes for each individual over the sample period, and then computing the average of these standard deviations across individuals. 
Table 4

Social Security Wage Index, Labor Income, and GNP

\begin{tabular}{|l|c|c|c|}
\hline \multirow{2}{*}{} & \multicolumn{3}{|c|}{ Growth rates } \\
\cline { 2 - 4 } & $\begin{array}{c}\text { Social Security } \\
\text { Wage Index }\end{array}$ & $\begin{array}{c}\text { Per Capita } \\
\text { Labor Income }\end{array}$ & $\begin{array}{c}\text { Per Capita } \\
\text { GNP }\end{array}$ \\
\hline $\begin{array}{l}\text { Mean } \\
\text { (\% per year) }\end{array}$ & 4.95 & 5.67 & 6.95 \\
\hline $\begin{array}{l}\text { Standard } \\
\text { deviation } \\
\text { (\% per year) }\end{array}$ & 2.12 & 2.45 & 2.73 \\
\hline
\end{tabular}

Correlations

\begin{tabular}{|l|c|c|c|}
\hline & $\begin{array}{c}\text { Social Security } \\
\text { Wage Index }\end{array}$ & $\begin{array}{c}\text { Per Capita } \\
\text { Labor Income }\end{array}$ & $\begin{array}{c}\text { Per Capita } \\
\text { GNP }\end{array}$ \\
\hline $\begin{array}{l}\text { Social Security } \\
\text { Wage Index }\end{array}$ & 1.00 & 0.72 & 0.71 \\
\hline $\begin{array}{l}\text { Per Capita } \\
\text { Labor Income }\end{array}$ & 0.72 & 1.00 & 0.92 \\
\hline $\begin{array}{l}\text { Per Capita } \\
\text { GNP }\end{array}$ & 0.71 & 0.92 & 1.00 \\
\hline
\end{tabular}

Note: Annual data, 1951-1997. All variables are measured in current US\$. 
Table 5: Estimating the sensitivity of income growth to SSWI growth

\# of ind's. in

Education Age group

group

\section{Married white females}

$\begin{array}{lc}<\mathrm{HS} & <46 \\ <\mathrm{HS} & 46-55 \\ <\mathrm{HS} & 56-65 \\ =\mathrm{HS} & <46 \\ =\mathrm{HS} & 46-55 \\ =\mathrm{HS} & 56-65 \\ >\mathrm{HS} & <46 \\ >\mathrm{HS} & 46-55 \\ >\mathrm{HS} & 56-65\end{array}$

All members of group: beta

$-0.10$

0.04

0.12

1.10

0.72

0.15

2.01

1.73

0.11

0.56

445
Single white females

$\begin{array}{lc}<\mathrm{HS} & <46 \\ <\mathrm{HS} & 46-55 \\ <\mathrm{HS} & 56-65 \\ =\mathrm{HS} & <46 \\ =\mathrm{HS} & 46-55 \\ =\mathrm{HS} & 56-65 \\ >\mathrm{HS} & <46 \\ >\mathrm{HS} & 46-55 \\ >\mathrm{HS} & 56-65\end{array}$

All members of group:

Married black females

$\begin{array}{lc}<\mathrm{HS} & <46 \\ <\mathrm{HS} & 46-55 \\ <\mathrm{HS} & 56-65 \\ =\mathrm{HS} & <46 \\ =\mathrm{HS} & 46-55 \\ =\mathrm{HS} & 56-65 \\ >\mathrm{HS} & <46 \\ >\mathrm{HS} & 46-55 \\ >\mathrm{HS} & 56-65\end{array}$

All members of group:
NA

NA

NA

5.31

$-0.02$

2.45

0.61

1.99

0.13

1.33

$-0.55$

$-0.16$

$-0.27$

0.41

$-0.26$

0.25

0.02

0.47

1.20

0.02

103
R2: ind. se(b)

0.96

0.43

0.26

0.88

0.25

0.21

0.80

0.35

0.75

0.17
NA

NA

NA

2.89

1.51

2.56

1.38

0.97

1.64

0.74

1.59

0.35

0.40

1.99

0.65

0.43

1.20

0.93

0.71

0.21

NA

0.96

2.22

0.00

0.61

NA

NA

2.01

NA

0.67
0.00

0.02

0.02

0.01

0.04

0.05

0.09

0.08

0.02

NA

NA

NA

NA

0.17

0.20

0.04

0.11

0.18

0.03

NA

0.02

0.02

0.01

0.08

0.07

0.04

0.07

0.06

0.05

NA

NA

0.14

0.01

NA

0.18

NA

NA

0.03

NA

NA
R2: group regression

0.01

0.16

0.15

0.16

0.67

0.54

0.46

0.83

0.15

0.80

NA

NA

NA

0.17

0.25

0.05

0.22

0.55

0.06

0.50

0.03

0.22

0.05

0.11

0.31

0.32

0.15

0.18

0.27

0.58

$\begin{array}{ll}N A & \\ 0.06 & 0.67\end{array}$

NA

0.26

0.01

0.00

0.27

NA

NA

0.06

NA

0.25
9 
Married white males

$\begin{array}{cc}<\mathrm{HS} & <46 \\ <\mathrm{HS} & 46-55 \\ <\mathrm{HS} & 56-65 \\ =\mathrm{HS} & <46 \\ =\mathrm{HS} & 46-55 \\ =\mathrm{HS} & 56-65 \\ >\mathrm{HS} & <46 \\ >\mathrm{HS} & 46-55 \\ >\mathrm{HS} & 56-65\end{array}$

All members of group:$$
37
$$

$4-228$

0.64

$-0.98$

$-3.15$

0.23

$-1.70$

3.48

1.80

$-0.62$

$-0.25$

4.91

0.84

0.84

2.53

1.00

1.14

3.05

1.19

1.60

0.81

0.01

0.03

0.01

0.03

0.04

0.02

0.04

0.04

0.02

NA

0.02

0.30

0.13

0.14

0.47

0.12

0.14

0.60

0.14

0.39

Single white males

$\begin{array}{lc}<\mathrm{HS} & <46 \\ <\mathrm{HS} & 46-55 \\ <\mathrm{HS} & 56-65 \\ =\mathrm{HS} & <46 \\ =\mathrm{HS} & 46-55 \\ =\mathrm{HS} & 56-65 \\ >\mathrm{HS} & <46 \\ >\mathrm{HS} & 46-55 \\ >\mathrm{HS} & 56-65\end{array}$

All members of group:

\section{Married black males}

$\begin{array}{cc}<\mathrm{HS} & <46 \\ <\mathrm{HS} & 46-55 \\ <\mathrm{HS} & 56-65 \\ =\mathrm{HS} & <46 \\ =\mathrm{HS} & 46-55 \\ =\mathrm{HS} & 56-65 \\ >\mathrm{HS} & <46 \\ >\mathrm{HS} & 46-55 \\ >\mathrm{HS} & 56-65\end{array}$

All members of group:

\section{Single black males}

$\begin{array}{cc}<\mathrm{HS} & <46 \\ <\mathrm{HS} & 46-55 \\ <\mathrm{HS} & 56-65 \\ =\mathrm{HS} & <46 \\ =\mathrm{HS} & 46-55 \\ =\mathrm{HS} & 56-65 \\ >\mathrm{HS} & <46 \\ >\mathrm{HS} & 46-55 \\ >\mathrm{HS} & 56-65\end{array}$

All members of group:

$\begin{array}{rr}N A & N A \\ N A & N A \\ N A & N A \\ N A & N A \\ N A & N A \\ N A & N A \\ N A & N A \\ 0.77 & 2.66 \\ -1.56 & 1.87 \\ \mathbf{0 . 0 0} & \mathbf{1 . 5 1} \\ & \\ & \\ -1.92 & 3.43 \\ 0.42 & 1.17 \\ -0.09 & 0.51 \\ -1.21 & 3.10 \\ -0.23 & 1.47 \\ -0.82 & 0.88 \\ \text { NA } & \text { NA } \\ -1.86 & 2.13 \\ -3.36 & 2.95 \\ -\mathbf{0 . 3 9} & \mathbf{0 . 4 7}\end{array}$

NA

NA

NA

NA

NA

NA

NA

0.04

0.20

NA

0.04

0.03

0.01

0.00

0.03

0.05

NA

0.05

0.02

NA

NA

NA

NA

NA

NA

NA

NA

0.51

NA

NA

1.43

0.77

1.43

0.77
0.04

0.19

0.19

0.01

0.13

0.38

NA

0.14

0.05

$\mathbf{0 . 4 3}$
NA NA NA NA NA NA NA 0.06 0.17 0.18

NA
NA
NA
NA
NA
NA
NA
0.51
NA
$\mathbf{0 . 5 1}$

Note: Individual regression is $\Delta \mathrm{Y}(\mathrm{ijt})=\alpha(\mathrm{ij})+\beta(\mathrm{j}) \Delta \mathrm{SSWI}(\mathrm{t})+\mathrm{u}(\mathrm{ijt})$ Group regression is $\Delta \mathrm{YBAR}(\mathrm{jt})=\alpha(\mathrm{j})+\beta(\mathrm{j}) \Delta \mathrm{SSWI}(\mathrm{t})+\mathrm{u}(\mathrm{jt})$, where $\Delta \mathrm{YBAR}(\mathrm{jt})$ is the change in the mean income of the group. 
Table 6: Estimating the sensitivity of income changes to the SSWI: Includes individuals with change in marital status during the sample period

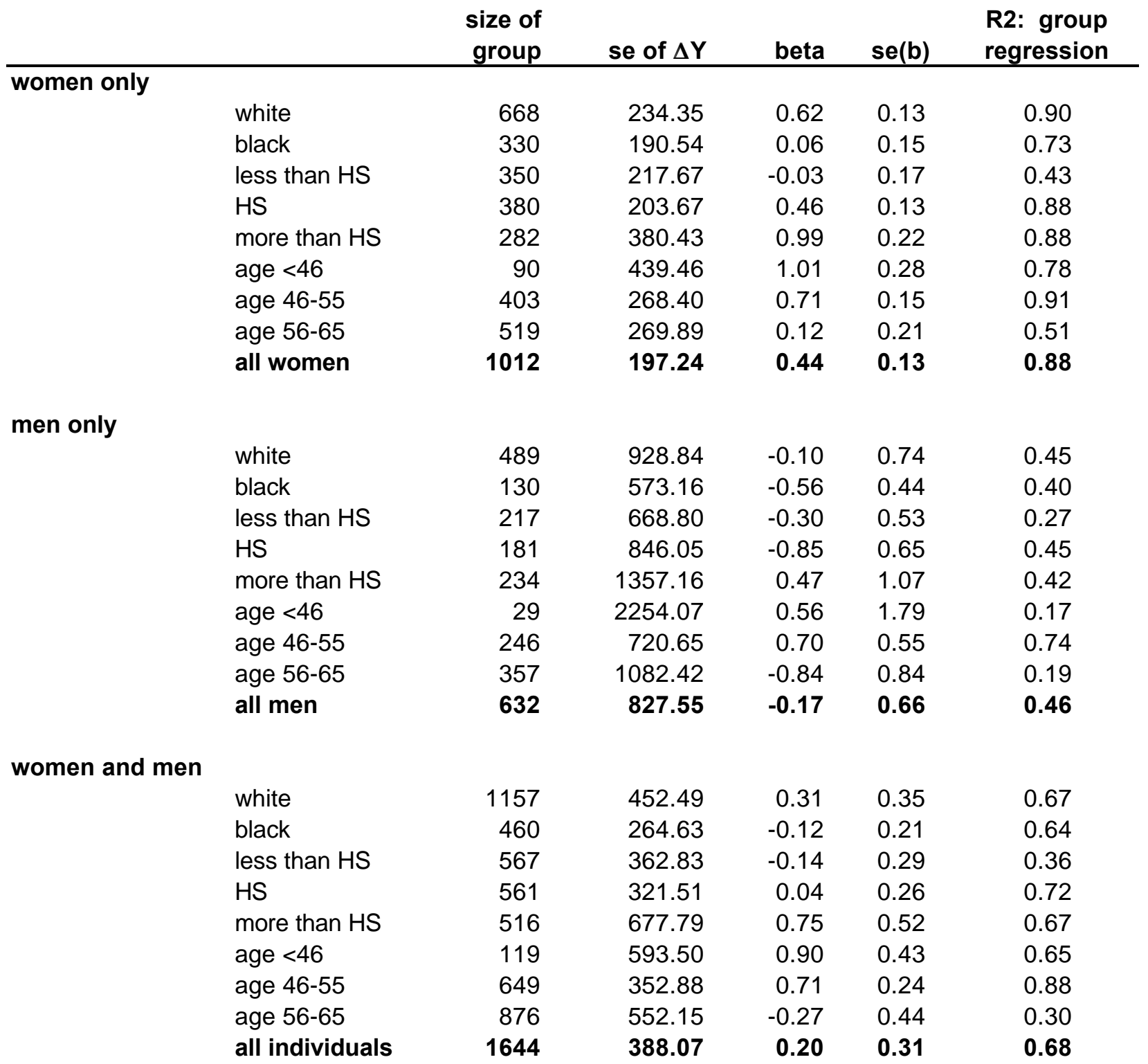

Note: Group regression is $\Delta \mathrm{YBAR}(\mathrm{jt})=\alpha(\mathrm{j})+\beta(\mathrm{j}) \Delta \mathrm{SSWI}(\mathrm{t})+\mathrm{u}(\mathrm{jt})$, where $\Delta \mathrm{YBAR}(\mathrm{jt})$ is the change in the mean income of the group. 

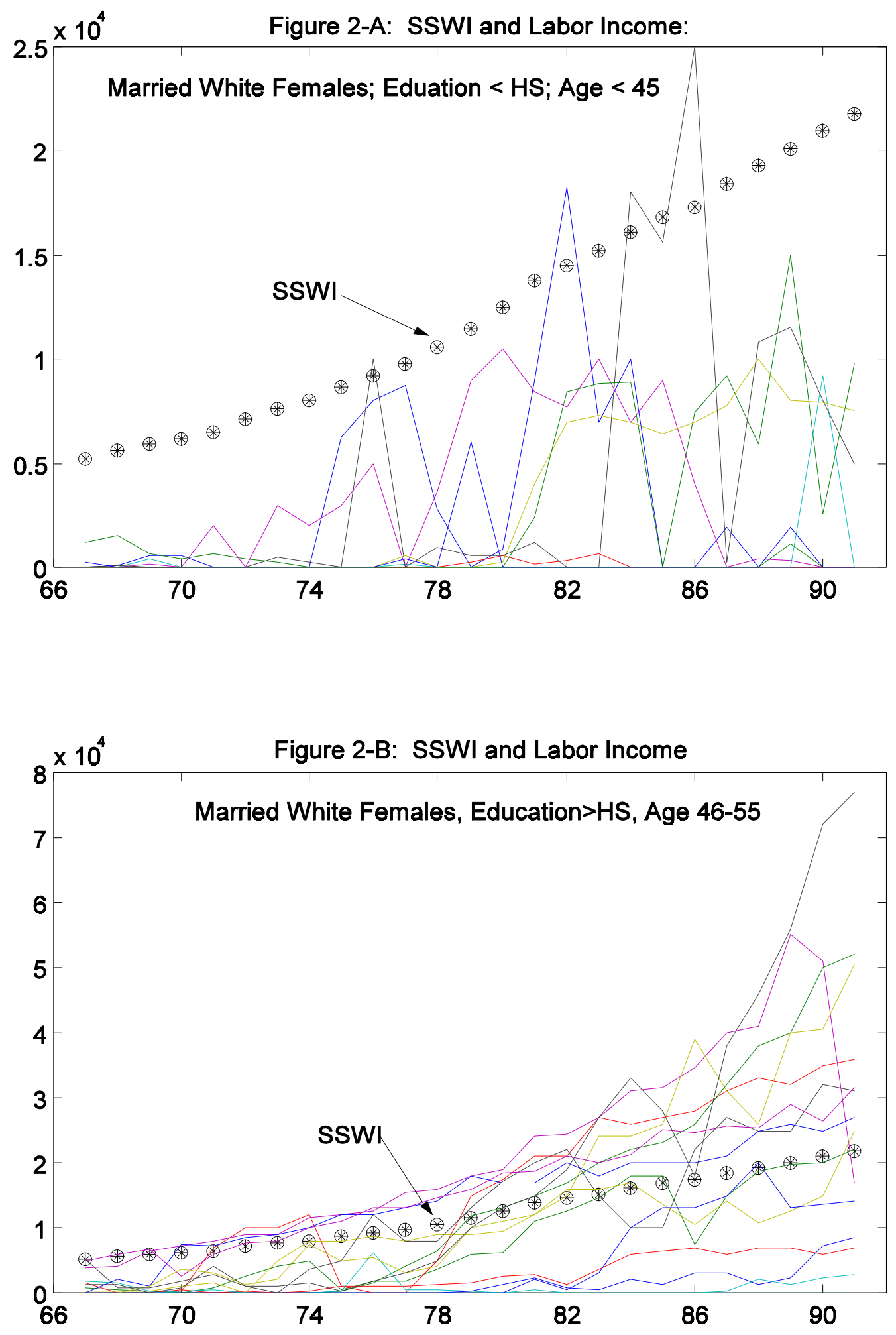
Figure 2-C: Labor income divided by SSWl

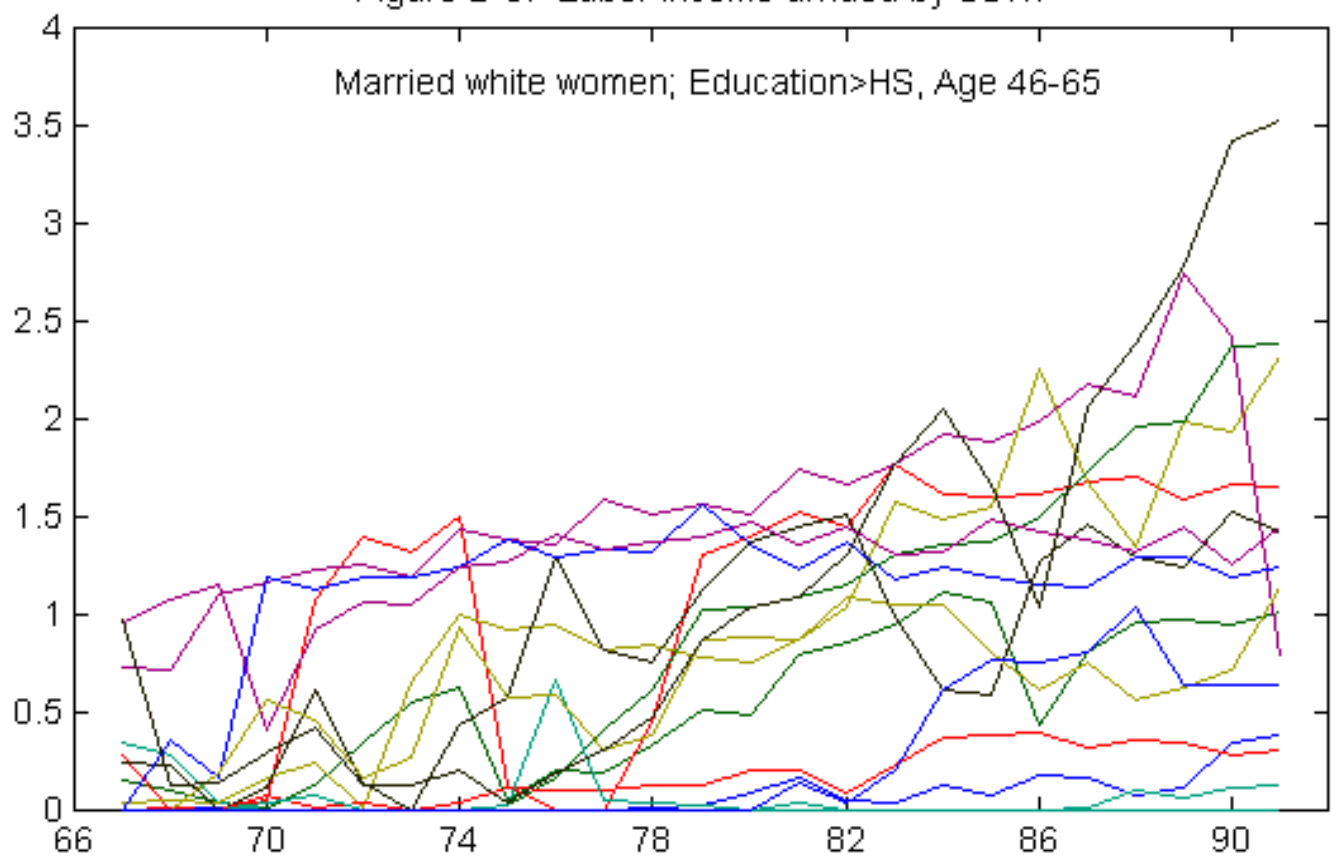

